\title{
La evolución de la cuestión nacional y la identidad española a través del Partido Socialista Obrero Español, 1974-1996: El proyecto socialista español de la transición democrática y más allá ${ }^{1}$
}

\author{
The evolution of the national question and Spanish identity through the Spanish Socialist \\ Workers Party, 1974-1996: The Spanish socialist project of the democratic transition and \\ beyond
}

Borja, García-Vázquez ${ }^{2}$

Universidad Autónoma de Nuevo León, México

(iD) https://orcid.org/0000-0003-0055-6917

do) $\underline{\text { https://doi.org/10.29105/pgc6.12-2 }}$

\section{RESUMEN}

El presente artículo es producto de una revisión documental que tuvo por objetivo estudiar la España planteada por el proyecto socialista de la transición, desde 1974 a 1996, a través de los programas electorales del Partido Socialista Obrero Español (PSOE) y su publicación oficial, la revista El Socialista. Se aplicó el método análisis, con la técnica de investigación de revisión documental. Se encontró que el PSOE constituye un actor clave de la historia de España por su aporte e impacto al desarrollo del conjunto de la sociedad española. Por este motivo, para entender España y su realidad, es necesario comprobar la visión del país mantenida por uno de sus principales partidos políticos. Se concluye que, a pesar del tiempo transcurrido, se mantiene la vigencia del proyecto socialista de la transición, como modelo de convivencia e integración de las distintas regiones que integran España.

Palabras claves: Democracia, socialismo, transición española, Felipe González.

\begin{abstract}
This article is the product of a documentary review that aimed to study the Spain raised by the socialist project of the transition, from 1974 to 1996, through the PSOE's electoral programs and its official publication, the journal El Socialista. The analysis method was applied, with the research technique of documentary review. It was found that the Spanish Socialist Workers Party (PSOE) constitutes a key actor in the history of Spain for its contribution and impact to the development of the whole of Spanish society. For this reason, to understand Spain and its reality, it is necessary to check the vision of the country maintained by one of its main political parties. It is concluded that despite the elapsed time, the validity of the socialist project of the transition remains, as a model of coexistence and integration of the different regions that make up Spain.
\end{abstract}

Keywords: Democracy, socialism, Spanish transition, Felipe González.

Recibido: 05 de Noviembre 2019 - Aceptado: 14 de Marzo 2020 - Corregido: 06 de Abril 2020

Cómo referenciar este artículo:

García-Vázquez, B. (2020). La evolución de la cuestión nacional y la identidad española a través del Partido Socialista Obrero Español, 1974-1996: El proyecto socialista español de la transición democrática y más allá. Politica Globalidad y Ciudadanía, 18-48. Recuperado de http://revpoliticas.uanl.mx/index.php/RPGyC/ article/view/145

\footnotetext{
1 Artículo de revisión derivado del proyecto de investigación propia del autor, sobre la evolución del pensamiento socialdemócrata en Iberoamérica.

2 Doctor en Métodos Alternos de Solución de Conflictos, por la Universidad Autónoma de Nuevo León. Profesor de Derecho Internacional público en la Facultad de Derecho y Criminología de la Universidad Autónoma de Nuevo León. Email: borjagarcia131@gmail.com
} 


\section{1.- INTRODUCCION}

El Congreso de Suresnes (Francia), celebrado en octubre de 1974, constituye el comienzo del actual Partido Socialista Obrero Español (en adelante PSOE), que desde su fundación en 1879, su supervivencia a la guerra civil y la posterior dictadura del general Francisco Franco Bahamonde, provocó una ruptura de continuidad del PSOE en suelo español que obligó a sus miembros a mantener su actividad desde el exilio y la clandestinidad. Suresnes marcó la transición entre los líderes históricos de la formación, con el nombramiento de Felipe González Márquez como Secretario General del PSOE, respaldado por la presencia de personalidades del socialismo europeo (como François Mitterand, Olof Palme, Pietro Nenni y Willy Brandt) o latinoamericanos (como Carlos Altamirano) sirviendo de preparación del retorno del PSOE a España como partido legalizado.

Previo a la muerte de Franco, el 20 de noviembre de 1975, había comenzado la descomposición del régimen, siendo en parte interpretado desde el PSOE como consecuencia de la situación económica que atravesaba el país, marcado por un contexto internacional en el que no encajaba el capitalismo de la dictadura, propiciando la desconfianza de sus propios integrantes (El Socialista, 1976a, pág. 14), que habían cimentado un sistema centralista, autoritario y represivo, basado en una unidad de España que negaba las nacionalidades históricas (reconocidas a través de los siglos, por medio de idiomas e instituciones autóctonas) y que representaba su lema "Una, grande, libre".

El 10 de febrero de 1977, los dirigentes del PSOE Luis Yáñez y Luis Gómez Llorente, depositaron en el Ministerio de la gobernación el acta notarial y la documentación necesaria para legalizar el PSOE, legalización que se hizo efectiva el 23 de febrero de 1977, al ser inscrita en el Registro de Asociaciones Políticas, por oficio del director general de Política Interior, Enrique Sánchez de León (El País, 1977) —el mismo día en que el Boletín Oficial del Estado publicaba el Real Decreto 214/1977, 18 de febrero, por el que se creaba la Embajada de España en la Unión de Repúblicas Socialistas Soviéticas-.

Terminaban así los cuarenta años de régimen para el PSOE y el conjunto de la izquierda española. Ante el nuevo horizonte democrático, el PSOE aparecía como un partido que se había definido en su XXVII Congreso, celebrado en Madrid el 5-8 de diciembre de 1976 —el primero que se llevaba a cabo por el partido en España desde 1932_, como partido de clases — luchando por la supresión de estas_- , de masas — para representar los intereses de los trabajadores_-, marxista — por ser esta su metodología de análisis de la realidad—, y democrático, tanto a nivel de funcionamiento interno, como externo en sociedad para lograr la construcción del socialismo (El Socialista, 1977a, pág. 2); consiguiendo que este Congreso representase la antesala 
ideológica de lo que supondría el proyecto socialista para las elecciones de 1977, sentándose las bases del mecanismo contenedor del pensamiento socialista español, que constituye el eje de estudio del presente trabajo: el programa, descrito en los siguientes términos: "El Partido tiene un texto fundamental: su programa máximo que, por seguir vigente, constituye la base de todo nuestro pensamiento y acción” (El Socialista, 1976c, pág. 5).

Los programas electorales constituyen el conjunto de tesis sobre las que se estructuran las propuestas de gobierno de una formación política, que han de servir de hoja de ruta de su administración en caso de lograr el triunfo, por lo que dichos programas son el instrumento sobre el que reposa toda la esencia de un partido, su gestión y su ideario en torno al modelo de país pretendido. Un instrumento de captación de votos, imbuido de la propaganda, sin que sea vinculante para gobernar, que atiende a la propia evolución de los partidos, y al aglutinamiento general de la sociedad. Como expresaba Kirchheimer (1969):

"Un partido general se interesa principalmente por el éxito electoral inmediato, al ampliar su seguimiento entre todos los grupos de la sociedad (...) un instrumento para lograr que sus miembros, anteriormente fuera del sistema, participen plenamente en el proceso político (...) realizando una función de integración política” (pág. xxvi).

La aparente indefinición en que parece encontrarse España hoy ha propiciado el auge de partidos independentistas (Esquerra Republicana de Catalunya, Junts per Catalunya, Compromis, Euskal Herria Bildu), nacionalistas regionales (Coalición Canaria, Partido Regionalista de Cantabria) y nacionalistas estatales como Vox; que promueven modelos identitarios alternativos en pos de cautivar al electorado, ya sea con la creación de un nuevo Estado, volviendo a las raíces tradicionalistas regionales, o buscando la identidad española en un pasado arcaico y desvinculado del presente.

La finalidad de este trabajo es estudiar la evolución de la cuestión nacional, y la identidad española en el socialismo democrático contemporáneo, a través de los distintos programas del PSOE, desde 1977 (con su incorporación al nuevo régimen democrático) hasta la finalización de la transición española (con el último gobierno de Felipe González Márquez en 1996) atendiendo al contexto histórico en el que fueron redactados los distintos programas, y a través de las publicaciones de la revista El Socialista, a fin de entender qué es España y el concepto de nación para el socialismo español.

\section{2.- MÉTODO}

\section{Diseño}

Revista Política, Globalidad y Ciudadanía, Vol. 6. No. 12, Julio - Diciembre 2020, Universidad Autónoma de Nuevo León, Monterrey, México, ISSN 2395-8448. 18-48. http://revpoliticas.uanl.mx/index.php/RPGyC/article/view/145 
La presente investigación responde a una metodología cualitativa, en palabras de Vasilachis de Gialdino (2006)“un proceso interpretativo de indagación, basado en distintas tradiciones metodológicas" a través del cual "quien investiga construye una imagen compleja holística (...) y conduce el estudio en una situación natural" (p. 24), con un diseño estructurado, de acuerdo a Mendizábal (2006) por ser un "protocolo lineal riguroso, con una secuencia unidireccional, cuyas fases se suceden en el tiempo" (p.66). Para tal fin, se seleccionó como método la interpretación de textos, con el objetivo de "comprender cada caso (Flick, 2002, pág. 228) alcanzando un enfoque de estudio comparado "a fin de entender los elementos comunes y específicos" del fenómeno investigado (Corbetta, 2007, pág. 37).

\section{Instrumentos}

Para la construcción del marco teórico-conceptual de la evolución política española desde los postulados del PSOE, se consultaron los siete (7) programas electorales del partido, publicados entre 1977 y 1996, y un total de cuarenta y nueve (9) números publicados por su revista El Socialista, de entre 1976 y 1996.

\section{Procedimiento}

Los programas electorales y los números publicados por la revista El Socialista, fueron consultados en las hemerotecas online del PSOE (https://www.psoe.es/el-socialista/hemeroteca/) y de la Fundación Pablo Iglesias (http://archivo.fpabloiglesias.es/index.php?r=hemeroteca/ElSocialista), empleándose como sistema los argumentos e ideas identificadas, para interpretarlas desde una visión crítica y razonada.

\section{3.- FUNDAMENTO TEÓRICO}

\section{El socialismo y la cuestión nacional}

En la teoría, el socialismo siempre se ha caracterizado por el internacionalismo, el cual, de acuerdo con Yañez-Barnuevo, es considerado como "parte constitutiva del socialismo" sin haberse desarrollado el concepto, quedándose en la superficie sin entrar al fondo de la cuestión, lo que lleva al autor a expresar que: "Tenemos que confesar que demasiado a menudo utilizamos esta idea — el internacionalismo - como una fórmula meramente ritual" (Yañez-Barnuevo, 1979, pág. 17). Frente al internacionalismo, encontramos la cuestión nacional, la cual ha sido analizada por el marxismo, motivo que nos lleva a exponer las posiciones de Rosa Luxemburgo, Josef Stalin y Vladimir Lenin, por ser sus estudios anteriores a 1921 — año en que el PSOE declinó su adscripción a la III Internacional—.

Rosa Luxemburgo trató esta cuestión en su artículo de 1908 El Estado-nación y el proleta- 
rio, haciendo un repaso a la noción de sociedad expuesta por Karl Kautsky, entendida como un conjunto de elementos burgueses ligados a un periodo concreto dentro del desarrollo de la sociedad moderna, que dan lugar a la aparición del Estado nacional. Sobre esta base, identifica una serie de elementos necesarios para el desarrollo de la burguesía, enriqueciendo la postura de Kautsky — limitada a las condiciones económicas, al centrarse exclusivamente en la necesidad de los industriales de contar con un mercado nacional en el que vender sus productos - considerando la necesidad de disponer de unas fuerzas armadas capaces de garantizar su independencia interna y su apertura mundial; un sistemas de comunicaciones, educación escolar y justicia; y la existencia de una política aduanera y financiera.

Con estos elementos se originan unas condiciones políticas que permiten el mantenimiento del poder de la clase burguesa, siendo un esquema que se repite en todos los Estados-nación, que de acuerdo a Luxemburgo, constituye una "forma histórica indispensable para la burguesía para pasar de la defensa nacional a la ofensiva, de la protección y la agrupación de su propia nacionalidad a la política de conquista y dominación de otras nacionalidades" (Luxemburgo, 1908).

A través de unas concretas condiciones políticas, es que se permite el desarrollo del patriotismo como elemento de lucha de clase, donde por iniciativa de la burguesía surge el Estado-nación como mecanismo de control de la mayoría, adherida a este proyecto a través de los elementos de cultura y democracia del nacionalismo; sintetizándolo Luxemburgo (1908) con esta máxima: “el Estado capitalista moderno es 'nacional' sólo en la medida en que le permite a la burguesía de una nacionalidad dada ejercer su dominación sobre toda la población mezclada del Estado".

Años más tarde, en 1913, Josef Stalin escribió el artículo El marxismo y la cuestión nacional, en el que enumera los elementos que dan lugar a la aparición de una nación - estructura distinta del Estado_-, recordando a su vez la afectación temporal que atenaza a este tipo de comunidades "sujeta a la ley del cambio, tiene su historia, su comienzo y su fin", exponiendo y argumentando su concepto de nación:

"Nación es una comunidad humana estable (no racial o tribal) históricamente formada y surgida sobre la base de la comunidad de idioma, de territorio, de vida económica y de psicología, manifestada ésta en la comunidad de cultura (...) sólo la presencia conjunta de todos los rasgos distintivos forma la nación” (Stalin , 1913).

De los planteamientos previos, podemos contraponer la figura del Estado a la de nación, fusionadas en la idea de Estado-nación, donde el cúmulo de elementos identitarios sirve de 
coartada para el sostenimiento de una estructura explotadora de clase, siendo esta posición encontrada en el discurso pronunciado en 1919 por Vladimir Lenin, ¿Qué es el poder soviético?:

"Mientras exista la dominación del capital, mientras la tierra siga siendo propiedad privada, el Estado lo gobernará siempre, incluso en la república más democrática y más libre, una pequeña minoría, integrada en sus nueve décimas partes por capitalistas o ricos” (Lenin, ¿Qué es el poder soviético?, 1919).

Lenin critica el Estado, asociándolo a la explotación burguesa, pero no ofrece una estructura alternativa al mismo, sino que, en contraposición, exclusivamente expone su variante soviética, al decir que:

"el poder del Estado ha sido organizado en Rusia de manera que únicamente los obreros y los campesinos trabajadores, excluidos los explotadores, constituyen los Soviets, organizaciones de masas a las que se trasfiere todo el poder público” (Lenin, ¿Qué es el poder soviético?, 1919).

Lenin no niega el Estado tras la revolución, al contrario, defiende el Estado por encima del concepto de nación, un argumento que defendió en 1918, en su artículo ;La patria socialista está en peligro!, en el que exhortaba a la población a que "el deber sagrado de los obreros y campesinos de Rusia es defender con abnegación la República de los Soviets" (Lenin, 1918), priorizando el Estado — soviético — sobre la nación — rusa — rompiendo con el esquema Estado-nación, lo que le lleva a concluir que la nación no es el elemento que motiva la defensa del territorio sino el ideal soviético de Estado, ligando esta postura a elementos de seguridad y protección de la clase obrera ante las injerencias extranjeras y burguesas. Por este motivo, Lenin desarrolla un listado de directrices destinadas a la salvaguarda del Estado, como el control sobre los alimentos, los medios de comunicación o el castigo de todos los elementos contrarrevolucionarios, en una proposición excluyente para las personas que no sean proletarios — frente a la posición incluyente defendida por el socialismo-.

\section{La antesala democrática (1974-1977)}

La naturaleza de España siempre ha sido tema de debate en las filas del pensamiento socialista, por la defensa de la libre autonomía de la agrupación y el país, constituyente de sus señas históricas, como se aprecia en el Congreso del PSOE de 1921, que supuso el rechazo del partido a Lenin y al ingreso en la III Internacional, controlada por la Unión Soviética. Si bien existía 
unidad en las filas socialista en cuanto al logro de la dictadura del proletariado, la divergencia surgió entorno al concepto de revolución entre los bolcheviques, que consideraban que el partido debía ser el encargado de forzar las circunstancias para que se produjese la revolución, frente a los socialistas, que creían que el partido solo debía encauzar la revolución cuando se diesen las circunstancias; además de por ser contrarios a la defensa de un partido único, global y jerarquizado como un ejército proletario en el que no existía lugar para el pensamiento disidente (como defendían los bolcheviques) lo cual chocaba frontalmente con la Base 1 del PSOE: "su autonomía para cuanto concierne a la táctica de lucha, por estimar que ésta ha de ser condicionada por las situaciones de cada momento, y la psicología de cada pueblo" (El Socialista, 1976a, pág. 11).

En 1974, durante el Congreso de Suresnes, se había debatido "sobre las nacionalidades ibéricas" analizando la situación desde la perspectiva de la lucha de clases y la emancipación de la clase trabajadora, considerando que la problemática existente solo podría superarse con la constitución de una República Federal conformada por las nacionalidades que integran el Estado español (El Socialista, 1976a, pág. 14). Posteriormente, en 1976, durante el XXVII Congreso el partido estableció una identificación del socialismo como una postura de rechazo a "cualquier camino de acomodación al capitalismo o a su simple reforma" abogando por una sociedad "autogestionaria" en la cual, "las nacionalizaciones y la planificación no suponen necesariamente el Socialismo" (E1 Socialista, 1976c, pág. 5).

En este congreso, entre otras materias, también se abordó la "cuestión nacional" ligada a Cataluña, interpretándose como una problemática originada en el contexto de lucha de clases entre la burguesía catalana y los terratenientes castellanos, que había derivado en la lucha por la autonomía de Cataluña, donde primaba el interés por lo local frente al desinterés por lo ocurrido en el resto de España, siendo vista esta actitud, en opinión del PSOE, como una contradicción incompatible para el internacionalismo obrero ante el nacionalismo defendido en Cataluña (El Socialista, 1976b, pág. 2). El propio Felipe González, consciente del centralismo y unitarismo que había caracterizado la dictadura, desde la postura federalista defendida por el partido, entendía que España (como instrumento al servicio de la población) debía ser utilizada como "un concepto plurinacional y plurirregional" a fin de armonizar la diversidad existente en el territorio, abogando por una mayor asunción de responsabilidades tanto en las estrategias socialistas a nivel de España como en la dirección del movimiento socialista, por "las distintas nacionalidades y regiones" (El Socialista, 1976a, pág. 4).

La cuestión nacional estará presente desde entonces, tratando de concebir una idea de lo que es España y su unidad, y de cómo encajar en ella los distintos nacionalismos surgidos en el país; así, en 1977 el partido defendía el federalismo como sistema integrador de los diversos sentires 
que se daban en la península, a través de la defensa de la "instauración de una república federal de trabajadores, integrada por todos los pueblos del Estado español" cuyo modelo de "una España socialista y libre" sólo sería posible por medio de un ejército capaz de defender "por la fuerza de las intromisiones o presiones de potencias concretas", abogando por la supresión de las bases militares estadounidenses en la país y la "creación progresiva de una tercera fuerza militar real entre países que se encuentren en vías de constituir un socialismo democrático" (El Socialista, 1977a, págs. 4-5); un planteamiento que rechazaba la incorporación de España a la Organización del Tratado del Atlántico Norte - OTAN — en favor de una mayor unidad con Europa y la creación —utópica - de una unión alternativa en el sentido del Pacto de Varsovia - aunque sin detallar la integración y estructura de esta fuerza-.

\section{Las primeras elecciones democráticas en 41 años: las elecciones generales 1977}

El 15 de junio de 1977, 3 meses y 21 días después de la legalización del PSOE, se celebraron las primeras elecciones generales libres desde febrero de 1936, obteniendo la victoria el partido Unión de Centro Democrático (UCD), seguido por el PSOE como segunda fuerza más votada, cuyo programa de 1977, compuesto por 27 páginas, se aproximaba a la cuestión nacional partiendo de la siguiente premisa: "España está constituida por una serie de nacionalidades y regiones diferenciadas" (PSOE, 1977, pág. 6). El partido era consciente de la realidad española, negada por la dictadura, sobre las diferentes "lenguas, tradiciones y culturas" que "configuran la personalidad propia de cada nacionalidad y región" de las que conforman España, siendo por este motivo, que defendía "la unidad del Estado español" a través de "una fórmula constitucional libremente pactada y abierta tanto a las diferencias entre las distintas nacionalidades y regiones como a la flexibilidad necesaria para su progresivo desarrollo y concreción" (PSOE, 1977, pág. 6) por medio de la protección de "la autonomía de cada nacionalidad y región con unas instituciones en el plano político y en el plano económico capaces de asegurar la solidaridad entre todos los ciudadanos del país", garantizando los derechos básicos de los españoles (PSOE, 1977, pág. 7).

El programa de 1977 dedicaba un apartado al ejército, por el lugar relevante que se consideraba ocupaban en la defensa del país, y con el objetivo de paliar la falta de estructuras, formación y medios adecuados que padecía desde la dictadura, a fin de "responder a las necesidades defensivas" de España, para lo cual se aducía que "todo militar debe sentirse pueblo y todo pueblo debe sentirse ejército" (PSOE, 1977, pág. 23); sin obviar la posición que debía ocupar el país en el contexto global, con un claro espíritu rupturista frente al pasado, oscilante "entre una política estrechamente nacionalista y aislacionista y una entrega de hecho a la dominación extranjera de las grandes potencias y de las empresas multinacionales” (PSOE, 1977, pág. 24). 
El PSOE veía España como una comparsa en el enfrentamiento de la guerra fría y quería una demarcación que permitiese al país consolidarse neutral ante esta lucha, y desarrollarse frente al ostracismo de las cuatro décadas previas, sin olvidar su carácter europeo (histórica y geográficamente) y la necesidad de formar parte del proceso integrador de Europa superando "nacionalismos caducos" y estableciendo "un marco para el desarrollo del socialismo, independiente de los imperialismos y en cooperación con el tercer mundo" para lograr "una Europa democrática y socialista” (PSOE, 1977, pág. 25); exposición que respondía al espíritu internacionalista que ha acompañado históricamente al socialismo, y que era interpretado en clave española por el fomento de la hermandad y la cooperación de los pueblos, en torno a las vecindades geográficas e históricas (Europa, el norte de África y Latinoamérica) y con la exhortación a la liberación de los pueblos oprimidos por "la dominación colonial o racista, o la opresión de las tiranías locales al servicio de los intereses imperialistas" a través de "una política concreta de cooperación técnico-científica y financiera" (PSOE, 1977, pág. 26).

En este contexto histórico, es necesario recordar que en aquel tiempo existía el Partido Socialista Popular (PSP) heredero del denominado Partido Socialista del Interior (PSI) creado por Enrique Tierno Galván en 1968, cuyo programa electoral de 1977 hacía mención a la cuestión nacional respecto de la administración del Estado, aspirando a construir un "Estado regional" en el que las nacionalidades y regiones históricas gozasen de autogobierno por medio de Estatutos, y la enseñanza pudiese ser impartida en "las lenguas vernáculas de las nacionalidades, aceptando la cooficialidad de las mismas con el castellano" (La Alcarria Obrera, 2011).

Tras las elecciones de 1977, el Comité Federal del PSOE hizo un llamamiento a la unidad del grupo catalán — Partido de los Socialistas de Cataluña - PSC - y del centro - PSP — (El Socialista, 1977b, pág. 1), logrando el 25 de enero de 1978, que Felipe González y Tierno Galván consiguiesen un acercamiento entre ambas formaciones, al reconocerse la ausencia de barreras ideológicas (E1 Socialista, 1978a, pág. 1); surgiendo en el mes de febrero, un acuerdo marco en el que se resolvieron las posibles discrepancias ideológicas, sindicales, organizativas y de empleo de símbolos indistintamente - el puño y la paloma, el yunque junto con la pluma y el libro, y el puño y la rosa- (El Socialista, 1978b, pág. 9); hasta que finalmente, el 30 de abril de 1978, ambas agrupaciones se fusionaron en un único PSOE, democrático, fiel al legado histórico - cuyo programa original, el conocido "programa máximo" de 1879, fue revisado por Marx y Engels - y con un proyecto para lograr una nueva sociedad (El Socialista, 1978c, pág. 3), con lo que 99 años después de la fundación del partido el 2 de mayo de 1879 en una taberna sita en la calle Tetuán, de Madrid — Casa Labra, aún abierta en la actualidad—, el PSOE volvió a ser uno. 
La Constitución española de 1978 y las elecciones generales de 1979

El 6 de diciembre de 1978, España votó en referéndum a favor de la Constitución, publicada el 29 de diciembre del mismo año en el Boletín Oficial del Estado y vigente desde entonces —en cuya redacción intervino como ponente del PSOE Gregorio Peces-Barba Martínez- la cual regula la cuestión nacional en numerosos puntos de su articulado, como su artículo 2 — relativo a "la indisoluble unidad de la Nación española" — artículo 3 -referente al castellano como lengua española oficial del Estado, y la cooficialidad de las lenguas así contempladas en los Estatutos de Autonomía, elemento de "patrimonio cultural" - o el artículo 145.1, que prohíbe el federalismo. En el debate de redacción del articulado, debemos destacar lo ocurrido en torno al artículo 2, ante la diversidad de opiniones que sostuvieron los ponentes, tratando de dar una definición de las nacionalidades, debiendo destacar la exposición de Peces-Barba, quien en un tono conciliador, sin entrar en el fondo del término nación, abordó la cuestión desde la consideración de España como un Estado plurinacional, "conjunto y la absorción de todas las demás" (Delgado-Iribarren García-Campero, 2005).

El texto constitucional, recogía a su vez la disposición transitoria octava, por la cual, una vez aprobada deberían convocarse elecciones, antes del 15 de junio de 1981, por lo que en cumplimiento de lo anterior, el 1 de marzo de 1979 se celebraron nuevas elecciones generales en España, que dieron la victoria a UCD, encontrándose de nuevo en segunda posición el PSOE; quien acudió con un programa breve - de 31 páginas - en el cual, conscientes de la nueva etapa democrática en que entraba el país, expresaban cómo constituía "uno de los retos más decisivos (...) hacer efectivo el derecho a la autonomía de las nacionalidades y regiones" al considerar que "la autonomía es el camino para acercar el poder a los ciudadanos" (PSOE, 1979, pág. 13).

Ante el centralismo que había caracterizado el periodo de la dictadura, el PSOE defendía la progresiva elaboración de Estatutos de Autonomía para lograr el objetivo de descentralización estatal, sin que se propusiese el establecimiento de una federación. Como disponía el propio programa, uno de los principios que contemplaba para cumplir con la obtención de la autonomía era "La preservación de la unidad de la nación española, la defensa de los intereses generales y el cumplimiento de los fines del Estado" (PSOE, 1979, pág. 13); a través de su descentralización — que requería de la cesión de competencias a las Comunidades Autónomas, la simplificación y unidad administrativa, y la coordinación de las haciendas autonómicas con la Hacienda General del Estado - y la ruptura de implicación con alguno de los bloques antagónicos de la guerra fría, manteniendo una posición de hermanamiento con los pueblos latinoamericanos y de condena de aquellos sometidos a la colonización (PSOE, 1979, págs. 17-19).

Ese mismo año, el 28 y 29 de septiembre, se celebró en Madrid el Congreso Extraordinario del PSOE, fecha que supuso un punto de ruptura histórica en las filas del PSOE, similar a lo 
ocurrido con el Congreso de 1921, al procederse al abandono del marxismo por el partido, al pronunciar Felipe González "No se puede tomar a Marx como un todo absoluto, no se puede, compañeros. Hay que hacerlo críticamente, hay que ser socialistas antes que marxistas" (El País, 1979).

\section{El PSOE hasta las elecciones generales 1982, y su primer gobierno}

Entre los días 28 y 30 de mayo de 1980, Felipe González presentó una moción de censura contra Adolfo Suárez, que, si bien no prosperó, desgastó su imagen, llevándole a presentar su dimisión el 29 de enero de 1981. Ese mismo año, el 23 de febrero, la recién nacida democracia enfrentó el intento de golpe de Estado, comandado por el teniente coronel de la guardia civil Antonio Tejero Molina, quien irrumpió en el Congreso de los Diputados durante la votación de investidura de Calvo-Sotelo, al mando de un grupo de doscientos guardias civiles al grito de "¡Quieto todo el mundo!”; al cual se sumó el mismo día el teniente general Jaime Milans del Bosch y Ussía, quien sublevándose con los golpistas, sacó los tanques a las calles de la ciudad de Valencia. La madrugada del 24 de febrero, su majestad el rey Juan Carlos dio un mensaje televisado en el que, dirigiéndose a todos los españoles, ordenaba a las autoridades civiles y a la Junta de Jefes del Estado Mayor, a que tomasen "todas las medidas necesarias para mantener el orden constitucional dentro de la legalidad vigente" (RTVE, 1981). A partir de este momento el golpe comienza a desmoronarse hasta que en la mañana del día 24, Tejero firma su rendición tras salir del Congreso de los Diputados, sin que se sepa a día de hoy de forma fehaciente, quien fue el organizador de esta frustrada sublevación.

Tres días después, el 27 de febrero se celebraron en toda España manifestaciones "por la libertad, la democracia y la Constitución", con más de un millón de personas en la ciudad de Madrid, donde al grito de “¡Dictadura no! ¡Democracia sí!”, “¡Libertad, libertad!” y "Depuración”, España expresó la intención de romper con el pasado (El Socialista, 1981, págs. 4-5). Superada la intentona golpista, la democracia siguió su curso normal, y la campaña de oposición, el desgaste político interno de UCD, y el recrudecimiento del terrorismo, entre otras causas, hizo que los españoles diesen en las urnas la mayoría al PSOE el 28 de octubre de 1982, una victoria que dio comienzo a una nueva etapa en el país, reflejada en la frase expresada por el entonces nuevo vicepresidente del gobierno, Alfonso Guerra González: “A España no la va a conocer ni la madre que la parió".

A las elecciones de 1982, el PSOE se presentó con un programa de 47 páginas, con el título "Por el cambio", incidiendo en la cuestión nacional con estas palabras: "El Estado ha de ser garante de la convivencia democrática y de la solidaridad entre los españoles y entre las nacionalidades y regiones de España” (PSOE, 1982, pág. 40); para lo cual hacía una remisión implícita 
al artículo 40 de la Constitución, a través del parafraseo de su contenido ${ }^{3}$ :

“(El Estado) tiene, además, según la Constitución, la obligación de promover las condiciones más favorables para el progreso social y económico y para una distribución equitativa de la renta personal y regional. Tiene también el deber de crear las condiciones que hagan real y efectiva la libertad y la igualdad entre los españoles” (PSOE, 1982, pág. 40).

La Constitución creó el Estado de las Autonomías, una fórmula de descentralización a medio camino entre el régimen centralista anterior y el federalismo prohibido, concibiéndose el Estado como propiedad constitucional de la ciudadanía, no de una minoría, ya que de lo contrario se correría el peligro de pervertir la función del Estado, y la gestión de los intereses de la ciudadanía:

"El Estado pertenece constitucionalmente a los ciudadanos. No corresponde a ninguna burocracia ni civil ni militar. Cuando esto se olvida, los intereses burocráticos se anteponen a los verdaderos intereses públicos, los aparatos burocráticos crecen más allá de lo razonable, se derrochan los recursos públicos, se debilita la creatividad de la sociedad y se tiende a llevar al ciudadano a una actitud pasiva de beneficiario o pasivo" (PSOE, 1982, pág. 40).

Para evitar el conformismo y la indiferencia ciudadana, la sociedad debía participar en el Estado, un instrumento a su servicio que dependía de él, a fin de que "el Estado se halle de verdad al servicio de los ciudadanos" (PSOE, 1982, pág. 40). En este contexto, ante la pluralidad de nacionalidades sentidas por la ciudadanía española y en pos de conseguir la descentralización estatal, el Estado de las Autonomías era entendido como el sistema para lograr dar cabida a esta pluralidad; donde el Estado operaría como garante de la actuación solidaria entre las Comunidades Autónomas - a través del correcto funcionamiento del Fondo de Compensación Interterritorial y el desarrollo de la política regional - calificando el programa este objetivo como "una de las tareas más hermosas y complejas de la democracia española (...) uno de los planes básicos de la política socialista” (PSOE, 1982, pág. 42).

Otro aspecto recogido por el programa de 1982 fue la posición de España en el mundo, de-

3 "Los poderes públicos promoverán las condiciones favorables para el progreso social y económico y para una distribución de la renta regional y personal más equitativa, en el marco de una política de estabilidad económica. De manera especial realizarán una política orientada al pleno empleo" (Cortes Españolas, 1978). 
fendiendo la necesidad de contar con un espacio libre de injerencias, que permitiese desarrollar la labor pacifica del país, contribuyendo "activamente a la causa de la paz, de la libertad, de la justicia y del progreso en el mundo (PSOE, 1982, pág. 45). Con esta premisa, y en un claro ejercicio de coherencia de pensamiento, el PSOE mantuvo y desarrolló la postura mantenida en los programas previos respecto de la condena y la lucha contra las diversas formas de opresión existentes, siendo conscientes de la especial situación de España en el mundo, como "país occidental y europeo, con una dimensión mediterránea y una proyección americana que lo diferencia de otras naciones europeas" situado "en la encrucijada de varias culturas y de varios continentes", encontrándose entre las prioridades del programa el fortalecimiento de las relaciones con América Latina, por medio de "la cooperación política, económica y cultural" (PSOE, 1982, pág. 46).

La llegada al poder de Felipe González va a tener por finalidad la culminación del Estado de las Autonomías, iniciado en 1979 — con la aprobación de los Estatutos de Autonomía de Cataluña y País Vasco - desarrollado durante 1981 - Galicia, Andalucía, Asturias, y Cantabria - y 1982 - La Rioja, Región de Murcia, Comunidad Valenciana, Aragón, Castilla-La Mancha, Canarias, y Navarra - a través del impulso de los Estatutos que estaban pendientes de aprobación —Castilla y León, Ceuta, Comunidad de Madrid, Extremadura, Islas Baleares, y Melilla—.

El primer gobierno socialista tuvo que afrontar la finalización de la descentralización estatal, en un escenario de crisis económica que arrastraba el país desde el comienzo de la crisis del petróleo de 1973, que llevó a que en 1983, la Organización para la Cooperación y el Desarrollo Económico - OCDE - augurase para España un índice de desempleo del 17\% y un crecimiento económico del 2\% (Díez, 1983, pág. 28), situación que manifestó Felipe González durante la cumbre de Paris organizada por el Partido Socialista Francés en enero de 1983, al expresar que existía "mucho egoísmo nacional y de esa manera no hay soluciones, porque de esta crisis no se sale con egoísmos nacionales, luchando cada país en solitario. Sin la solidaridad entre las naciones no hay salida" (El Socialista, 1983a, pág. 11); unido al problema del terrorismo, principalmente de ETA, ante el cual González, preguntado sobre las negociaciones con la banda respondía: "No estoy dispuesto a que se ponga en cuestión la unidad de España. La discusión, el debate, será siempre dentro de los límites de la Constitución” (El Socialista, 1983a, pág. 15); una situación que motivó una guerra sucia iniciada para combatirlo — recordando que desde la promulgación de la amnistía habían sido asesinados 200 miembros de las fuerzas de seguridad del Estado- e investigada por el gobierno, por ser considerada esta guerra sucia, en palabras de González "el asesinato, lo practique quien lo practique” (El Socialista, 1983b, pág. 11).

En diciembre de 1984, el PSOE celebró su XXX Congreso, "España, compromiso de solidaridad", el primero celebrado tras haber logrado el partido el gobierno del país, en el que se 
definió la postura del PSOE respecto de la permanencia de España en la OTAN, pese a haberse opuesto anteriormente. En este Congreso, Felipe González dio muestra de su pragmatismo político, como sintetizaban sus palabras:

"Si yo tuviera que tomar la decisión de incorporar España a la Alianza, creo que no la tomaría, pero estamos dentro de la Alianza, con países como Francia, Alemania, Gran Bretaña, Canadá, EEUU, Holanda o Bélgica (...) soy absolutamente consciente de que ésta es la realidad de España (...) cuando hablo de mantener el estatus actual lo estoy haciendo con la cabeza, no con el corazón, con una gran frialdad, analizando qué es lo que favorece a España y qué es lo que la perjudica” (El Socialista, 1984a, pág. 3).

Con 266 votos a favor, 394 en contra y 23 abstenciones, se decidió que el partido no pidiese la salida de España de la OTAN (El Socialista, 1984b, pág. 3) acto que configuró la posición del país como actor internacional, europeo y occidental ${ }^{4}$, consciente y realista ante los cambios que atravesaba el planeta, en un determinado escenario económico, donde primaba la apertura ante el aislamiento que arrastraba el país, como recogió la resolución del Congreso:

“España, como país europeo occidental, participa del proceso de cambio global que se produce en la actual etapa del capitalismo. De una sociedad aislada del exterior estamos pasando a una sociedad mucho más abierta, en la que se han intensificado extraordinariamente los intercambios con los demás países, a nivel social, económico e ideológico” (El Socialista, 1985, pág. 2).

Fruto del XXX Congreso, se elaboró el documento "Una política de paz y seguridad" donde se reconocía la inminente incorporación económica e institucional, así como su posición geoestratégica clave, en Europa; razón por la que se consideraba que la permanencia de España en la OTAN contribuía a garantizar la paz y la seguridad, al no perturbar el equilibrio de fuerzas de la guerra fría (El Socialista, 1985b, pág. 7). Del mismo modo, ante la situación exterior, en el plano interno del país, el Estado de las Autonomías era visto como "una exigencia del desarrollo y consolidación de la democracia” (E1 Socialista, 1985a, pág. 14).

España no podía ocupar su posición europea y occidental sin democracia, por lo que conscientes de la situación, se reafirmó en el Congreso que "La continuidad del proceso autonómico

4 Una posición que se consolidó con la firma por Felipe González, del Acta de Adhesión de España a las Comunidades Europeas, el 12 de junio de 1985 .

Revista Política, Globalidad y Ciudadanía, Vol. 6. No. 12, Julio - Diciembre 2020 Universidad Autónoma de Nuevo León, Monterrey, México, ISSN 2395-8448. 18-48. http://revpoliticas.uanl.mx/index.php/RPGyC/article/view/145 
es la mejor garantía para la defensa y promoción de la identidad propia de los distintos pueblos de España” (El Socialista, 1985a, pág. 14), exposición que delimitaba la hoja de ruta a seguir por el Partido, en favor de mantener la descentralización y el fomento de la responsabilidad y la solidaridad entre las Comunidades Autónomas y sus ciudadanos, iguales pese a sus señas propias de identidad, en la unidad de España.

El segundo gobierno del PSOE: las elecciones generales 1986

El 1 de enero de 1986 España se incorporó oficialmente a las Comunidades Europeas, cuya primera muestra fue el establecimiento de la igualdad del sistema tributario español respecto del resto de miembros europeos, a través del Impuesto sobre el Valor Añadido - IVAque sustituyó 24 impuestos indirectos, encareciendo algunos productos básicos (El Socialista, 1986a, pág. 8); a su vez, el 19 de enero del mismo año, como consecuencia de la incorporación europea, España estableció relaciones diplomáticas con Israel - 35 años después de su fundación - una reparación de la ruptura con el pueblo judío, iniciada con su expulsión en 1492 (El Socialista, 1986b, pág. 3).

El 30 de enero, se produjo la jura de la Constitución ante las Cortes, por su alteza real el príncipe de Asturias, Felipe de Borbón y Grecia, al alcanzar este su mayoría de edad, en un acto que simbolizaba el sometimiento al derecho y al sistema parlamentario representativo y el compromiso de servicio a las instituciones, y de lealtad al Rey, del futuro monarca — actual Felipe VI-, como recogen las palabras del entonces presidente del Congreso de los Diputados, Gregorio Peces-Barba Martínez:

“Alteza Real: con el Juramento que vais a prestar estáis simbolizando vuestro sometimiento al Derecho, vuestra aceptación del sistema parlamentarlo representativo que nuestra Constitución establece, vuestro compromiso de servicio a las instituciones y a los ciudadanos y vuestra lealtad al Rey. Hoy es un día grande para la democracia, para la Monarquí, y para todos los hombres y mujeres de esa España viva y plural de las Autonomías" (Congreso de los Diputados, 1986).

La España de 1986 es monárquica, europea, abierta al establecimiento de nuevas relaciones internacionales y práctica en lo político, como demostró el referéndum sobre la permanencia de España en la OTAN, una arriesgada maniobra política que mostraba la importancia que representaba la democracia para el gobierno socialista, al anteponer la decisión de la ciudadanía sobre un tema que era trascendental para el conjunto del país. Celebrado el 12 de marzo de 1986, tras una campaña en la que se sucedieron los movimientos a favor y en contra de la per- 
manencia española en la OTAN, se impuso el sí, con el 52,53\% de los votos, con un porcentaje de participación en el referéndum del 59,73\% (E1 Socialista, 1986c, pág. 3).

El 11 de abril de 1986, el PSOE celebró un Comité Federal extraordinario para reprobar internamente - por 82 votos a favor, 2 en contra y 23 abstenciones - la falta de disciplina de algunos miembros que se mostraron contrarios a la petición de voto favorable por el sí, durante la campaña sobre el referéndum de la Alianza Atlántica, anteponiendo criterios personales a la decisión adoptada previamente por el partido, lo cual fue entendido como un acto de deslealtad política; e igualmente, durante el Comité Federal, Manuel Chaves, secretario de asuntos sociales, económicos y sindicales de la Comisión de la Ejecutiva Federal, y coordinador del equipo de trabajo de elaboración del programa electoral de 1986, expuso el avance del mismo, indicando que la línea a seguir sería similar al programa de 1982 (El Socialista, 1986d, pág. 3).

El programa electoral de 1986, titulado "Para seguir avanzando, por buen camino" constaba de 124 páginas, destacando el tratamiento que se efectuaba de la cuestión nacional, no como un fenómeno aislado del país, sino en relación a Europa - cuestión que se explica por la incorporación del país a la CEE — . En concreto, el apartado dedicado por el programa a tratar ese tema llevaba por rubrica “Adaptación a Europa y a los nuevos instrumentos de gestión”.

Para el PSOE, tal y como recoge su programa del 86, el garante de la aplicación y funcionamiento de la política comunitaria era el Estado, requiriéndose para ello de "la coordinación, lealtad, confianza y solidaridad de los distintos poderes públicos" (PSOE, 1986, pág. 108), partiendo de la necesidad de organizar y coordinar el funcionamiento de la Administración del Estado tanto en el centro y las periferias, como entre el Gobierno y las Autonomías (PSOE, 1986, pág. 97). El programa de 1986 mantenía así el continuismo en el abordaje de la cuestión nacional — salvo la novedad de adaptación europea - como consolidación del proyecto del Estado de las Autonomías iniciado con la Constitución de 1978, recordando en su texto como al momento de acceder al cargo los socialistas, el proyecto se encontraba en sus inicios, calificando de trascendental "la superación del Estado autoritario y centralizado" que caracterizó al régimen anterior — que mantuvo adeptos contrarios a la reforma — y que había sido posible “gracias al empeño de la mayoría de los españoles” (PSOE, 1986, pág. 105).

La consolidación institucional se preveía a través de la coordinación y la cooperación entre las administraciones públicas, donde el gobierno de la Nación era el único legitimado democráticamente para definir y ejecutar políticas nacionales (PSOE, 1986, pág. 106) confirmando así la apuesta por un Estado de las Autonomías, donde el gobierno de la Nación era un primus inter pares; mientras que en el marco internacional, el Partido se presentaba a las elecciones, con una labor continuista de la cooperación de su gobierno ante América Latina "en pro de la paz, la libertad, la defensa de los derechos humanos y el logro de mayores cotas de bienestar y progreso 
para sus pueblos" (PSOE, 1986, pág. 111); donde todos los lineamientos de exposición de política exterior respondían a la necesidad de España de contar con una credibilidad internacional en el marco de las relaciones que mantenía con otros países, lo cual formaba parte de un proceso que requería desarrollo y fortalecimiento, que se basaba en "Garantizar la integridad territorial, la soberanía nacional y la seguridad de España (PSOE, 1986, pág. 112).

Durante la campaña de estas elecciones, por primera vez se empleó en España el mensaje telefónico como publicidad electoral, donde el receptor de la llamada escuchaba la voz grabada del propio presidente del gobierno (El Socialista, 1986e, pág. 5). El 22 de junio, el pueblo español cumplió con su cita ante las urnas, con una participación del 70,77\%, en la que el PSOE se mantuvo como la principal fuerza política del país, con el respaldo del $44,06 \%$ de los votos (E1 Socialista, 1986f, pág. 1), garantizando con ello el desarrollo de las políticas socialistas en España, como expresaba Felipe González la noche del 22 de junio:

"Estos resultados hacen posible la continuidad y estabilidad del proyecto de progreso en el que hemos venido trabajando. Reiteramos la voluntad de que nuestra acción de gobierno esté presidida por un espíritu de diálogo, acuerdo y cooperación con todas las fuerzas políticas y sociales, así como las Comunidades Autónomas, corporaciones locales y demás instituciones del Estado” (E1 Socialista, 1986f, pág. 3).

\section{El tercer gobierno del PSOE: las elecciones generales 1989}

Del 20 al 22 de junio de 1986 se celebró el XVII Congreso de la Internacional Socialista, en Lima - Perú - siendo la primera vez que se reunía en un país de América Latina (El Socialista, 1986, pág. 7), una región que al igual que España, estaba afectada por la crisis económica mundial, agravada por el déficit estructural de estos países, la desigualdad, la inexistencia de políticas a largo plazo y de un proyecto nacional (Casilda, 1986, pág. 10).

Con una derecha descabezada, tras la renuncia de Manuel Fraga Iribarne al frente del partido Alianza Popular — AP — algunas voces de las filas socialistas alertaban de las repercusiones que podía tener esta situación sobre la democracia española, al generar un panorama de ausencia de alternativa que convirtiese el voto en el PSOE "en el voto por el mal menor, por lo malo conocido" (Paramio, 1986, pág. 3). La crisis afectaba a España, y existía descontento por la situación económica del momento: la cesta de la compra había ascendido de 20.315 pesetas en 1982 a 30.270 pesetas en 1987 (El Socialista, 1987a, pág. IV), siendo muestra de la inflación del país, que afrontaba un proceso de reconversión industrial desde la promulgación del Real Decreto-Ley 30 de noviembre de 1983; además, en 1987 el gobierno tuvo que afrontar: una moción de censura que no prosperó por 195 votos en contra, frente a 67 votos a favor y 71 
abstenciones (E1 Socialista, 1987a, pág. IV); unos enfrentamientos en la localidad de Reinosa, en Cantabria, ante la reconversión industrial de la industria Forjas y Aceros — que daba trabajo a 1.763 personas de las 13.000 que habitaban la localidad — la cual preveía la pérdida de 463 puestos de trabajo (E1 País, 1987) que se saldaron con la muerte del trabajador Gonzalo Ruiz el 5 de mayo (Delgado , 1987); y el recrudecimiento de la actividad terrorista de ETA, con atentados como el de Hipercor, el 11 de junio en Barcelona - con 21 muertos, de los cuales cuatro eran niños, y 45 heridos_-, o el de la casa cuartel de Zaragoza el 11 de diciembre - con 11 muertos, entre los que se encontraban cinco niños y un adolescente, y alrededor de 90 heridos(Ceberio Belaza, 2018).

Frente a este escenario, el PSOE celebró entre el 22 y el 24 de enero de 1988 su XXXI Congreso, en el cual Felipe González manifestó su firme convicción en el partido que lideraba “capaz de articular el conjunto de la sociedad española, capaz de darle cohesión al Estado, capaz de asumir su responsabilidad en la lucha contra el terrorismo, en la superación de la crisis económica y capaz de llevar adelante las responsabilidades del Gobierno" (El Socialista, 1988, pág. 3). En el contexto de este Congreso, se presentaron los primeros resultados del llamado “Programa 2000”. Una comisión de trabajo del partido, que comprendería de 1987 a 1990, para recoger propuestas en materia de economía, política y sociología, con la intención de obtener conclusiones sobre cuáles serían las tendencias para el año 2000 (El Socialista, 1987b, pág. 3) con la siguiente finalidad: "Reconstruir una ideología operativa, un programa básico de estrategias capaz de propiciar la innovación social que España reclama” (Escudero, 1987, pág. 7). De este Congreso debe destacarse la aprobación, por mayoría absoluta, en los Estatutos Federales del partido, de la creación de un sistema de cuotas para garantizar la presencia de la mujer en la directiva del partido, en un porcentaje que no fuese inferior al 25\% (El Socialista, 1988, pág. 15) y de igual forma, con la aprobación por el Gobierno del Real Decreto 1/1988, de 22 de febrero, se reguló la incorporación de la mujer a las Fuerzas Armadas.

Con estas medidas, el PSOE mostraba su compromiso con las mujeres, en una clara maniobra de aperturismo social, necesario para el régimen democrático que se estaba consolidando en aquellos años; una democracia a la que Felipe González aludía en el discurso de cierre del XXXI Congreso, pronunciando unas palabras que pueden aplicarse hoy, en pleno siglo XXI:

"La democracia sigue siendo el menos malo de todos los sistemas, el más digno, el más noble, el que es capaz de poner al descubierto los defectos de cada cual. Pero la democracia tienes sus reglas; y a veces uno tiene el sentimiento de que inconsciente o conscientemente esas reglas se están vulnerando. Esas reglas se vulneran con grave daño cuando se desprestigia la política y a los politicos en general: todos son iguales, todos 
vienen a aprovecharse, sean de donde sean y (añaden algunos en voz baja) si no se han aprovechado es que son tontos. ¿En qué quedamos?” (El Socialista, 1988, pág. 13).

En enero de 1989, España asumió por primera vez la presidencia semestral de la Comunidad Europea, la cual estuvo marcada, como expuso el entonces ministro de Asuntos Exteriores, Francisco Fernández Ordoñez, por Europa, el Mercado Interior, los ciudadanos y el espacio social europeo (El Socialista, 1989a, pág. 4); ese mismo año, siete meses antes de lo previsto, Felipe González decidió convocar elecciones para el 29 de octubre (El Socialista, 1989b, pág. 3 ) en las cuales habría conseguido por tercera vez mayoría absoluta, con el respaldo del 39,55\% de los votos, tras una participación del 69,92\% (El Socialista, 1989c, pág. 1) si no hubiese sido por la decisión de la Junta Electoral Provincial de Murcia de dar el noveno escaño de esta provincia a Izquierda Unida - IU—, en perjuicio del PSOE (El Socialista, 1989d, pág. 4), aunque fue una mayoría absoluta de facto, al obtener 175 escaños de los 176 necesarios, debido a que los diputados del partido Herri Batasuna, estuvieron ausentes durante toda la legislatura. El 20 de noviembre de ese año, el diputado Iñaki Esnaola, sufrió un atentado, en el que murió el diputado Josu Muguruza, siendo nombrados como sustitutos Rafael Diez Usabiaga y Ángel Alcalde, respectivamente, pero todos ellos, junto a Itziar Aizpurúa y Jon Idígoras, fueron suspendidos durante toda la legislatura, por no utilizar la fórmula oficial de acatamiento de la Constitución (El País, 1989) (El País, 1991).

A esta cita electoral, el PSOE acudió con el programa "España en progreso" de 76 páginas, con la visión puesta en 1992, año en que se iban a celebrar numerosos eventos de trascendencia para los españoles: "La creación del Mercado Único Europeo, la conmemoración del Quinto Centenario del Descubrimiento de América, la celebración de la Exposición Universal de Sevilla, los Juegos Olímpicos de Barcelona y la elección de Madrid como Capital Cultural de Europa"; siendo visto ese año como "una oportunidad para impulsar España" y demostrar el grado de integración y apertura internacional alcanzado por el país, viéndose Europa, desde el proyecto socialista, como el medio necesario para fortalecer la situación interna (PSOE, 1989, págs. 5-8).

Se deduce del programa que la visión socialista respecto del país comprendía tres posiciones interconectadas: España en Europa, como parte del proyecto de integración; España con Europa, en la defensa y promoción de las condiciones que propugna; y España frente a Europa, al no negar el desarrollo de un proyecto nacional propio, en paralelo al desarrollo de la Unión Europea. En el mismo sentido, Europa era vista como un medio, y no un fin, "para conseguir un espacio común con más empleo y progreso social” (PSOE, 1989, pág. 8), dedicando en el plano cultural, un apartado a las lenguas del país considerándolo "un patrimonio enriquecedor, cuya 
preservación, estímulo y difusión son objetivos deseables" para lo cual se preveía la promoción de "medidas e incentivos específicos para la conservación y conocimiento de estas culturas y lenguas, tanto en España como en su proyección internacional” (PSOE, 1989, pág. 60).

E1 PSOE comprendía la riqueza cultural del país, tanto a nivel nacional, como en los distintos niveles regionales, asumiendo la importancia de defender y difundir este patrimonio inmaterial de todos los españoles, como elemento cohesionador dentro y fuera de nuestras fronteras: "La cultura española aspira a consolidar su papel en el mundo (...) Los socialistas españoles reivindicamos el papel de la cultura en la construcción de Europa” (PSOE, 1989, pág. 61). Asimismo, en el documento se consolidaba la evolución programática del PSOE en Iberoamérica, fijando como principios orientadores de su actividad "la paz en Centroamérica, la democratización del Continente y el desarrollo y progreso de sus pueblos"; situación en que destacó la defensa a los incipientes procesos democráticos de Chile y Paraguay (PSOE, 1989, pág. 75).

\section{El cuarto gobierno del PSOE hasta las elecciones generales 1993}

A comienzos de 1990, la Unión Soviética se estaba desmoronando con el consecuente efecto que esto producía en los movimientos de izquierda del mundo entero. El mes de noviembre de 1989 los berlineses acabaron con el muro que había dividido su ciudad durante 28 años, mientras que los países del Este europeo llevaban años organizándose para lograr la independencia, y el ejército soviético seguía combatiendo en la guerra de Afganistán. Los discursos de izquierda necesitaban una renovación, incluidos los socialdemócratas, ante el riesgo de caer en el anquilosamiento ideológico y la incapacidad de ofrecer un modelo a seguir. Por este motivo, el 18 de enero de 1990, se presentó el borrador del manifiesto del Programa 2000, fruto de las investigaciones realizadas los tres años previos, con el fin de renovar el proyecto socialista (El Socialista, 1990a, pág. 7), cuya versión definitiva se publicó en junio de ese año (Escuerdo Zamora, 1990, pág. 6).

El documento, considerado la guía del proyecto socialista para alcanzar un cambio social y acabar con la explotación — con el apoyo mayoritario de la sociedad - reconocía el papel que cumple el Estado, a quien se le requería la asunción de nuevas atribuciones tendentes a garantizar el reparto de la prosperidad y el sostenimiento de la democracia (El Socialista, 1990b, pág. 7). A través de este documento, el PSOE defendía una formula federalista — pese a utilizar la terminología constitucional de Estado de las Autonomías - por entender que solo a través de ella es como se podía lograr una verdadera democracia, rompiendo con el sistema centralista, en un ejercicio de coherencia con el pensamiento progresista, sin omitir también la crisis que atravesaba en aquellos años el comunismo: 
"Tras setenta y tres años de utopías revolucionarias, convertidas en terror político, la propia Unión Soviética ha hecho saltar en mil pedazos el referente ideológico del comunismo (...) la renovación del proyecto del socialismo democrático adquiere así el compromiso de convertirse en plataforma para el encuentro de toda la izquierda" (El Socialista, 1990b, pág. 10).

El PSOE consideraba que la democracia es el camino, y la socialdemocracia debía ser la piedra angular sobre la que descansase la política de la izquierda, al entenderse que:

"La democracia es una conquista histórica que ha de seguir siendo cincel para modelar el cambio social hacia una nueva sociedad, en la que el poder, la renta y la riqueza estén repartidas de tal modo que creen las bases materiales para la completa emancipación social” (El Socialista, 1990b, pág. 10).

Ante el descalabro soviético — cuyo último presidente, Mijail Gorbachov, fue el primer y único dirigente de este país que visitó España, entre el 26 y 28 de octubre de 1990 (El Socialista, 1990c, pág. 13) - el PSOE veía en la socialdemocracia un sólido cimiento frente a otras alternativas, gracias a los principios que habían caracterizado el movimiento: "Talante de seriedad, de rigor, de sentido de la disciplina, de sentido de la solidaridad (...) de mantenimiento por encima de todo de un espíritu solidario con los compañeros y de acatamiento a las normas de funcionamiento democrático interno del partido" (Tezanos, 1990, pág. 9).

La situación internacional fue reconocida en el XXXII Congreso del PSOE, celebrado en noviembre de 1990. En él, si bien se celebró la caída del Muro de Berlín —el mismo día de apertura del congreso - como el propio González expresó, se corría el riesgo de que el fracaso comunista constituyese la sacralización del sistema capitalista, frente a la idea socialista del mercado como un instrumento de generación de riqueza que debe redistribuirla con la ejecución de políticas dirigidas a ese fin (El Socialista, 1990d, pág. 3). Ante la deriva comunista, el socialismo se enfrentaba ante el reto de asumir el pleno liderazgo de la izquierda y plantear alternativas y soluciones a los problemas de la sociedad. Para ello, como se reconoció en el VII encuentro sobre el futuro del socialismo, celebrado en Madrid el 12-14 de diciembre de 1991, una de las claves era la recuperación del internacionalismo por parte de la izquierda, para lograr un fortalecimiento de la solidaridad mundial entre los países del norte y del sur (El Socialista, 1991, pág. 9). Ese internacionalismo fue el aplicado por el PSOE en estos años, logrando posicionar a España en la esfera internacional como un defensor incondicional de la paz a cualquier precio, como demostró el aporte al bloqueo internacional contra Sadam Hussein o la 
intervención humanitaria durante la guerra de los Balcanes, la celebración de la conferencia de paz de Madrid en octubre de 1991, la firma del Acuerdo de Maastricht, o la propuesta de Felipe González de crear la ciudadanía europea.

Entre los días 19 y 20 de junio de 1992, el PSOE celebró su Comité Federal, del cual se aprobó la resolución “Objetivo 97”, en el que conscientes de este nuevo escenario mundial, se fijaba como meta que España llegase a ser "un país a la cabeza del desarrollo económico, un país eficiente y un país socialmente integrado" no sin antes reconocer que para ello se requeriría un esfuerzo ciudadano: "Una meta colectiva, no solo por su importancia, sino porque implica un cambio cultural: superar la ilusión de la ganancia fácil y valorar la importancia del esfuerzo, del trabajo bien hecho" (E1 Socialista, 1992, pág. 7).

España atravesaba una delicada situación como consecuencia del paro y los escándalos de corrupción que estaban salpicando al gobierno, poniendo en peligro el proyecto socialista. Ante este escenario, Francisco Fernández Marugán fue nombrado coordinador de los trabajos de elaboración del programa electoral de las elecciones de 1993 (El Socialista, 1993a, pág. 36) y Felipe González decidió adelantar las elecciones al 6 de junio de ese año, ante el bloqueo institucional que se desarrollaba en el país (El Socialista, 1993b, pág. 21).

El documento obtenido de estos trabajos fue "El programa de la mayoría", de 98 páginas, en cuyo comienzo se explicaba cómo España ocupaba el puesto prioritario de sus políticas, sin olvidar Europa ni el Estado de las Autonomías — bajo la mención de la cohesión nacional y la solidaridad-(PSOE, 1993, pág. 3). El Estado de las Autonomías era una realidad, pero ante la descentralización alcanzada, se debía evitar el riesgo de caer en la ruptura, y en la desaparición de la nación española por el éxito de las naciones que la conforman: "Un Estado tan descentralizado como el español, debe plantearse el mantenimiento de los factores de vertebración que nos configuran como una nación, en la que todos los ciudadanos gozan de idénticos derechos en cualquier lugar del territorio" (PSOE, 1993, pág. 81).

El país se encontraba en plena recesión económica, aunque se avistaban ya elementos de recuperación. Pese a esta situación, el Estado había conseguido la descentralización iniciada con la Constitución de 1978, sin omitir la unidad entre las distintas regiones: "España es uno de los Estados más descentralizados del mundo habiendo solucionado unos de sus problemas históricos. La cohesión territorial es el complemento ineludible de la cohesión social" (PSOE, 1993, pág. 8). A pesar de la descentralización alcanzada, esto no implicaba un desentendimiento de la cuestión cultural como algo exclusivo de cada autonomía, sino como parte de un proyecto común nacional (PSOE, 1993, pág. 70); y en el ámbito internacional, el programa de 1993 contemplaba la continuidad del proyecto de consolidación europea, en vista de lograr un mayor protagonismo de España en la integración económica, así como conseguir un posicionamiento 
en el eje Mediterráneo a través de la defensa de la paz y los derechos humanos, de acuerdo al mandato de Naciones Unidas para construir un nuevo mundo tras la superación de la guerra fría, fijando sus ejes de actuación “en el ámbito del Mediterráneo y en la consolidación de la Comunidad Iberoamericana de Naciones" (PSOE, 1993, pág. 9), al ser imposible negar los especiales vínculos existentes entre España e Iberoamérica, por su "vinculación histórica y cultural" que "constituye un espléndido activo humano y un valioso instrumento diplomático para ambas partes" (PSOE, 1993, pág. 95).

En 1993, recién colapsado el mundo comunista, la socialdemocracia del PSOE mostraba su compromiso con el internacionalismo a través de la solidaridad y la cooperación entre los Estados, y la promoción y defensa de la democracia, los derechos humanos y la paz; así como la protección de los desfavorecidos, tal y como reconocía el programa al decir que "La inmigración legal y controlada es algo positivo para nuestro país"; a la vez que declaraba el "firme compromiso de lucha política, jurídica y cultural contra el racismo y la xenofobia" (PSOE, 1993, págs. 64-65), propuestas que permitieron que Felipe González consiguiese imponerse en las urnas, con el 38,68\% de los votos de una participación del $77.28 \%$ de la ciudadanía (El Socialista, 1993c, pág. 20), pero las elecciones de 6 de junio de 1993 constituyeron su última victoria electoral y la última alcanzada por el PSOE hasta el año 2004.

\section{La derrota electoral de González en las elecciones generales 1996}

Como manifestaba Felipe González ante la proximidad del XXXIII Congreso del PSOE, celebrado el 18-20 de marzo de 1994, el paro era la principal preocupación de la sociedad española (Gonzalez, 1993, pág. 6). La última legislatura socialista en años se enfrentó al problema del empleo, al que se sumaría la credibilidad del sistema bancario español — con el caso Banestoy la incertidumbre en torno a los Grupos Antiterroristas de Liberación o GAL, llegando a ser preguntado abiertamente el presidente por el periodista Iñaki Gabilondo en una entrevista de 1995 sobre si había organizado él estos grupos.

Son los años del “¡Váyase señor González!” como acuñó José María Aznar —líder del Partido Popular — durante el debate sobre el estado de la nación de 1994, y el rechazo de los presupuestos generales de 1995, los primeros que no fueron admitidos en la historia del país, llevando a una situación de crispación que desembocó en la disolución de las Cortes el 8 de enero de 1996 y a la convocatoria de elecciones para el 3 de marzo de ese mismo año.

A esta cita electoral el PSOE acudió con un programa sin título, de 226 páginas, el más extenso redactado hasta el momento. El partido asumía la delicada situación que atravesaba el país - la cual podríamos hacer extensible a la actualidad-:

"las elecciones de marzo van a tener lugar en medio de una crisis política innegable. Se

Revista Política, Globalidad y Ciudadanía, Vol. 6. No. 12, Julio - Diciembre 2020, Universidad Autónoma de Nuevo León, Monterrey, México, ISSN 2395-8448. 18-48. http://revpoliticas.uanl.mx/index.php/RPGyC/article/view/145 
ha extendido una sensación de malestar sobre el modo en que funciona el sistema democrático (...) nuestra vida pública atraviesa una fase de ensimismamiento y de tensiones que nos impiden centrar la atención en los auténticos retos del futuro (...) los españoles se encuentran hoy perplejos ante lo que puede pasar, y demandan claridad sobre las perspectivas de futuro" (PSOE, 1996, pág. 10).

El documento abría con una declaración de intenciones del país: "Vivimos abiertos a Europa y al mundo"; a la par que exponía que "ya no somos diferentes" (PSOE, 1996, pág. 7) mostrando cómo España había abandonado definitivamente el ostracismo de las décadas pasadas, habiendo alcanzado una posición de país desarrollado, posicionado internacionalmente e integrado en el contexto europeo, abriendo el espectro de posibilidades al futuro nacional: "Hemos unido nuestra suerte a la del resto de los países del continente, y nuestra presencia en la Unión Europea nos permite afrontar con optimismo muchos de los retos que depara el futuro" (PSOE, 1996, pág. 12).

A pesar de las oportunidades que podía abrigar el porvenir, el PSOE era consciente de la necesidad de la unidad y el esfuerzo nacional para lograr el aprovechamiento de las mismas. El desgaste político provocado por los incansables años de crisis, la proliferación de los casos de corrupción que salpicaban al gobierno y la consolidación de la derecha, como alternativa realista, llevaron al partido a una posición de necesaria evolución:

"Queremos cambiar, pero sin destruir lo que hemos logrado (...) movilizar de nuevo a todos los sectores sociales que ambicionan un futuro mejor (..) que nuestro mensaje sea escuchado también por esa parte de la sociedad que está excesivamente tensa y crispada, que siente desafección por los asuntos politicos (...) pero nos preocupa que un hipotético triunfo de la derecha sea el primer paso para cuestionar parte de lo que hemos logrado (...)” (PSOE, 1996, pág. 9).

Ante el descontento popular hacia la política y las instituciones, el PSOE recordaba cómo se había concluido el proyecto de descentralización, cumpliéndose el objetivo del Estado de las Autonomías (PSOE, 1996, pág. 8) que permitía la continuidad de la unidad nacional, precisándose de una materialización a través de un efectivo desarrollo de las infraestructuras: "El territorio debe quedar unido por una vasta red de carreteras y de telecomunicaciones, que aumente su competitividad y reequilibre unas zonas con otras" (PSOE, 1996, pág. 17).

A la par, sostenía la importancia de la pluralidad cultural del país, no como un sumatorio de fenómenos regionales aislados, sino como complemento de la riqueza del conjunto de España, 
motivos por los que defendía un proyecto plural y único en sí mismo:

"Queremos ofrecer ante el problema nacional una cultura política de lealtad, mostrando nuestro reconocimiento y asunción del pluralismo lingüístico, cultural e histórico de España. Y frente a quienes tratan de explotar el rechazo hacia quienes no son como ellos, nos comprometemos a garantizar la tolerancia ante los hechos diferenciales de nuestras nacionalidades y regiones" (PSOE, 1996, págs. 17-18).

Para ello, se exhortaba "la difusión de la lengua y cultura españolas mediante las instituciones creadas y los medios de comunicación públicos” (PSOE, 1996, pág. 89), asegurando el aprendizaje de todos los alumnos tanto del español, como de la lengua propia de las Comunidades Autónomas (PSOE, 1996, pág. 51) y "la enseñanza del español y de la lengua propia de la Comunidad Autónoma de acogida para los inmigrantes de otras lenguas y sus familias" (PSOE, 1996, pág. 91).

Al exterior, España/Europa — como un ente indivisible_-, no era independiente del nuevo escenario geopolítico propiciado por el fracaso soviético, donde si bien se mantenía el espíritu internacionalista propio del socialismo, se asumía la importancia que desempeñaba la seguridad de otros países para la seguridad propia nacional:

"Desde nuestro punto de vista como socialistas, ni España ni Europa pueden concebir su futuro desentendiéndose de lo que sucede en el borde mismo de las fronteras del continente (...) la solidaridad en nuestra política hacia ese grupo de países (en referencia al Este de Europa y el norte de África) y hacia Latinoamérica no es solo un imperativo moral sino un requisito de nuestra propia seguridad” (PSOE, 1996, págs. 18-19).

En el mismo sentido, la cooperación con Iberoamérica, considerada fundamental para la política exterior de España fue abordada desde el plano educativo, a través de formación y asistencia técnica (PSOE, 1996, pág. 101), y de programas de intercambio deportivos (PSOE, 1996, pág. 109); pero sobre todo por medio del impulso de un proceso de integración iberoamericano:

"Debemos lograr asentar un mayor espacio social entre América Latina y España y ayudar a vertebrar la cohesión de la región en sí. Este objetivo impulsa y justifica nuestro esfuerzo por constituir progresivamente una Comunidad Iberoamericana de Naciones" (PSOE, 1996, pág. 217). 
De nada sirvió la propuesta de un sólido modelo nacional e internacional de alternativa. El PSOE obtuvo el 31,83\% de los votos, perdiendo por un estrecho margen ante el PP, que obtuvo el 37,19\% (Congreso de los Diputados, 1996). A principios de mayo de 1996, José María Aznar llegó al Palacio de la Moncloa, la que sería su nueva residencia durante casi una década, marcando así el final del proyecto socialista iniciado en 1982.

\section{4.-CONCLUSIONES}

España no se puede entender sin el PSOE. Desde la abstención histórica de formar parte en la III internacional — como manifestación de independencia ante las injerencias extranjeras de la Unión Soviética - hasta la anexión al sistema europeo y la entrada en la OTAN — como posicionamiento del país en la esfera internacional occidental, a pesar de su rechazo inicial— el socialismo español ha sido consciente de las implicaciones de cada decisión adoptada — sin olvidar los actos criminales cometidos por el GAL_, la importancia del internacionalismo, la solidaridad y la cooperación entre Estados, junto con la defensa de la paz y el diálogo, elementos indispensables para el cumplimiento del socialismo.

Originariamente el partido proyectó una idea de España como una república federal de trabajadores, cuya defensa correspondía a las fuerzas armadas, como representación del pueblo, en coordinación con Europa y en oposición a las intromisiones extranjeras. La promulgación de la Constitución española de 1978, llevó al abandono del republicanismo, aceptando un régimen monárquico parlamentario en favor de garantizar la estabilidad en los comienzos de la democracia, sin que por ello se abandonasen los objetivos de descentralización progresiva, dentro de la unidad española, a través del fortalecimiento de la solidaridad entre sus distintas regiones, el respeto y la defensa de las diversas identidades culturales, el fomento de la responsabilidad democrática del país y la defensa de los trabajadores.

España se concebía como un primus inter pares, que debía garantizar la armonía y la convivencia entre sus distintas regiones, evitando cualquier ruptura. Su titularidad no era exclusiva de un grupo o una concreta identidad, sino que agrupaba al conjunto de quienes viven en ella, encargados de velar por su integridad a través de la responsabilidad democrática al interior, y con las fuerzas armadas al exterior. Progresivamente, a medida que se iba consolidando la posición del país en Europa y el conjunto de occidente, se comenzó a impulsar los vínculos con las proximidades geográficas e históricas del norte de África y del conjunto de América Latina.

La acumulación de escándalos políticos, el problema del paro, tres huelgas generales, y el acoso de la oposición política, desencantaron al electorado, poniendo fin a trece años de gobierno socialista. Terminaba así un proyecto que había logrado acrecentar la descentralización del antiguo régimen, dando lugar a una España concienciada de su pasado, con el respeto y la 
protección de la cultura y las lenguas españolas; abierta al exterior, tanto europea como internacionalmente - y muy especialmente con Iberoamérica - así como al interior — con la conclusión del Estado de las Autonomías y la incorporación de la mujer en los distintos ámbitos de la sociedad española-; plural, por la defensa y difusión de la cultura y las lenguas españolas; pacífica, dialogante, y sobre todo democrática.

\section{REFERENCIAS}

Casilda, R. (1986). Deuda latinoamericana. El Socialista, (409).

Ceberio Belaza, M. (2018). ETA y el coche bomba: los atentados más sangrientos. En El País: https://elpais.com/politica/2018/04/29/actualidad/1525026725_974459.html

Congreso de los Diputados. (1986). Diario de sesiones del Congreso de los Diputados, número 265, II Legislatura. En Congreso de los Diputados. Consultado el 24 de enero de 2020: http://www.congreso.es/public_oficiales/L2/CONG/DS/PL/PL_265.PDF

Congreso de los Diputados. (1996). Elecciones Generales de 3 de marzo de 1996. En Congreso de los Diputados. Consultado el 25 de enero de 2020: https://app.congreso.es/consti/ elecciones/generales/resultados.jsp?fecha=03/03/1996

Corbetta, P. (2007). Metodología y técnicas de investigación social. Madrid: McGraw-Hill.

Cortes Españolas. (1978). Constitución española. En Boletín Oficial del Estado.

Consultado el 18 de enero de 2020: https://www.boe.es/legislacion/documentos/ ConstitucionCASTELLANO.pdf

Delgado , J. (1987). La viuda de Gonzalo Ruiz presentará una querella contra la Guardia Civil por los sucesos de Reinosa. En El País, Consultado el 20 de enero de 2020: https://elpais. com/diario/1987/07/14/espana/553212013_850215.html

Delgado-Iribarren García-Campero, M. (2005). Sinopsis del artículo 2 de la Constitución española de 1978. En Congreso de los Diputados. Consultado el 20 de enero de 2020: http://www.congreso.es/consti/constitucion/indice/sinopsis/sinopsis.jsp?art=2\&tipo=2

Díez, L. (1983). La cuesta de enero. El Socialista, 28.

El País. (1977). El PSOE histórico, legalizado. En El País. Consultado el 21 de enero de 2020: https://elpais.com/diario/1977/02/24/espana/225586829_850215.html 
El País. (1979). Felipe González: "Hay que ser socialistas antes que marxistas. En El País. Consultado el 22 de enero de 2020: https://elpais.com/diario/1979/05/22/ espana/296172016_850215.html

El País. (1987). Desesperada respuesta a una reconversión. En El País. Consultado el 21 de enero de 2020: https://elpais.com/diario/1987/03/13/espana/542588401_850215.html

El País. (1989). Expulsados del Congreso los diputados de HB al no utilizar la fórmula oficial para acatar la Constitución. En El País. Consultado el 22 de enero de 2020: https://elpais. com/diario/1989/12/05/espana/628815612_850215.html

El País. (1991). El Congreso suspende de sueldo durante un año a los tres diputados de Herri Batasuna. En El País. Consultado el 22 de enero de 2020: https:/elpais.com/ diario/1991/06/12/espana/676677625_850215.html

El Socialista. (5 de diciembre de 1976a). Especial XXVII Congreso del PSOE. El Socialista, (1).

El Socialista. , Especial XXVII Congreso del PSOE. El Socialista, (3).

El Socialista. (8 de diciembre de 1976c). Especial XXVII Congreso del PSOE. El Socialista, (4).

El Socialista. (1 de febrero de 1977a). El Socialista, 91(1).

El Socialista. (3 de julio de 1977b). El Socialista, 91(11).

El Socialista. (29 de enero de 1978a). El Socialista, 92(41).

El Socialista. (5 de marzo de 1978b). El Socialista, 92(46).

El Socialista. (7 de mayo de 1978c). El Socialista, 92(55).

El Socialista. (3 de marzo de 1981). El Socialista.

El Socialista. (2 de febrero de 1983a). El Socialista, 11.

El Socialista. (28 de diciembre de 1983b). El Socialista(342), 11.

El Socialista. (13 de diciembre de 1984a). Extra XXX Congreso. El Socialista.

El Socialista. (16 de diciembre de 1984b). Extra XXX Congreso. El Socialista.

El Socialista. (1 de enero de 1985a). El Socialista, (372).

El Socialista. (16 a 31 de diciembre de 1985b). El Socialista, (395). 
García-Vázquez, $B$

46

El Socialista. (16 a 31 de enero de 1986a). El Socialista, (397).

El Socialista. (1 a 15 de febrero de 1986b). El Socialista, (398).

El Socialista. (12 a 31 de marzo de 1986c). El Socialista, (401).

El Socialista. (16 a 30 de abril de 1986d). El Socialista, (403).

El Socialista. (16 de junio de 1986e). El Socialista, (407).

El Socialista. (22 de junio de 1986f). El Socialista, (408).

El Socialista. (16 de julio de 1986g). El Socialista, (409).

El Socialista. (15 de enero de 1987a). El Socialista, (421).

El Socialista. (15 de mayo de 1987b). El Socialista, (429).

El Socialista. (22 a 24 de enero de 1988). Especial 31 Congreso. El Socialista.

El Socialista. (31 de enero de 1989a). El Socialista, (470).

El Socialista. (15 de septiembre de 1989b). El Socialista, (485).

El Socialista. (31 de octubre de 1989c). El Socialista, (489).

El Socialista. (15 de noviembre de 1989d). El Socialista, (489).

El Socialista. (31 de enero de 1990a). El Socialista, (494).

El Socialista. (30 de junio de 1990b). El Socialista, (504).

El Socialista. (31 de octubre de 1990c). El Socialista, (512).

El Socialista. (15 de noviembre de 1990d). El Socialista, (513).

El Socialista. (31 de diciembre de 1991). El Socialista, (540).

El Socialista. (30 de junio de 1992). El Socialista, (552).

El Socialista. (febrero de 1993a). El Socialista, (560).

El Socialista. (abril de 1993b). El Socialista, (562).

El Socialista. (mayo de 1993c). El Socialista, (563).

Escudero, M. (1987). Definir el modelo socialista del año 2000. El Socialista(443).

Escuerdo Zamora, M. (1990). Programa 2000: un balance de cuatro años. El Socialista, (503). 
Flick, U. (2002). Introducción a la investigación cualitativa. A Coruña: Fundación Paideia Galiza.

Gonzalez, F. (1993). Un debate abierto. El Socialista, (567).

Kirchheimer, O. (1969). Politics, Law, and Social Change. New York: Columbia University Press.

La Alcarria Obrera. (2011). Programa electoral del PSP en 1977. En La Alcarria Obrera. Consultado el 13 de enero de 2020: https://laalcarriaobrera.blogspot.com/2011/12/ programa-electoral-del-psp-en-1977.html

Lenin, V. (1918). ¡La patria socialista está en el peligro!. En Marxists.org. Consultado el 14 de enero de 2020: https://www.marxists.org/espanol/lenin/obras/oe12/leninobrasescogidas07-12.pdf

Lenin, V. (1919). ¿Qué es el poder soviético?. En Marxists.org. Consultado el 13 de enero de 2020: https://www.marxists.org/espanol/lenin/obras/oe12/lenin-obrasescogidas09-12.pdf

Luxemburgo, R. (1908). El Estado-nación y el proletario. En Marxists.org. Consultado el 14 de enero de 2020: https://www.marxists.org/espanol/luxem/1908/estado-nacion.1908.pdf

Mendizábal, N. (2006). Los componentes del diseño flexible en la investigación cualitativa. En I. Vasilachis de Gialdino, Estrategias de investigación cualitativa. Barcelona: Gedisa, 65-106.

Paramio, L. (1986). Un proyecto de futuro para España. El Socialista, (420).

PSOE. (1977). Programa electoral de 1977. Madrid: Partido Socialista Obrero Español. PSOE. (1979). Programa electoral de 1979. Madrid: Partido Socialista Obrero Español. PSOE. (1982). Programa electoral de 1982. Madrid: Partido Socialista Obrero Español. PSOE. (1986). Programa electoral de 1986. Madrid: Partido Socialista Obrero Español. PSOE. (1989). Programa electoral de 1989. Madrid: Partido Socialista Obrero Español. PSOE. (1993). Programa electoral de 1993. Madrid: Partido Socialista Obrero Español. PSOE. (1996). Programa electoral de 1996. Madrid: Partido Socialista Obrero Español. 
RTVE. (1981) Mensaje del rey Juan Carlos tras la intentona golpista del 23-F. En Archivo RTVE. Consultado el 20 de enero de 2020: http://www.rtve.es/alacarta/videos/fue-noticiaen-el-archivo-de-rtve/archivo-mensaje-del-rey-juan-carlos-tras-intentona-golpistadel-23/393739/

Stalin , J. (1913). El marxismo y la cuestión nacional. En Marxists.org. Consultado el 13 de enero de 2020: https://www.marxists.org/espanol/stalin/obras/oe1/Stalin\%20-\%20 Obras\%20escogidas.pdf

Tezanos, J. (1990). Transformación y continuidad en el socialismo español. El Socialista, (512).

Vasilachis de Gialdino, I. (2006). La investigación cualitativa. En I. Vasilachis de Gialdino, Estrategias de investigación cualitativa (23-64). Barcelona: Gedisa.

Yañez-Barnuevo, J. (1979). La dimensión internacional del proyecto socialista. El Socialista, 93(128), 17. 